\title{
Correction to: Primary evaluation of an air-cooling device to reduce oral mucositis: a pilot study in healthy volunteers
}

\author{
C. Blacker ${ }^{1}\left(\mathbb{D} \cdot\right.$ T. Kamsvåg $^{1}$ (C) $\cdot$ R. S. Bejhed ${ }^{1}\left(\mathbb{D} \cdot\right.$ G. Ljungman $^{1}(\mathbb{C}$
}

Published online: 29 January 2021

๑) Springer Science+Business Media, LLC, part of Springer Nature 2021

\section{Correction to: Medical Oncology (2020) 37:110 https://doi.org/10.1007/s12032-020-01431-4}

Unfortunately, the online published article has an error in the references of the figures in the text under the Results section. Instead of referring to Fig. 3 (Reported adverse events), we refer to Fig. 2 (Digital thermal image of a test subject). The correct figure referred should be Fig. 3 .

Furthermore, the reference to Fig. 1 in the Statistical section and the reference to Fig. 3 in the Result section, were mistakenly added in the editing of the final version and this was missed during the final proof reading process.

In the Subjects and methods section, the Fig. 1 (Schematic drawing of cooling device) refers to The air-cooling device subsection and Fig. 2 (Digital thermal image of a test subject) to the Methods subsection.

Publisher's Note Springer Nature remains neutral with regard to jurisdictional claims in published maps and institutional affiliations.
C. Blacker and T. Kamsvåg have contributed equally to this work.

The original article can be found online at https://doi.org/10.1007/ s12032-020-01431-4.

\section{Blacker}

christopher.mats.blacker@akademiska.se

1 Department of Women's and Children's Health, Uppsala

University, Entrance 95, SE-751 85 Uppsala, Sweden 